\title{
Endovascular Treatment and Selective Image Guided Partial Resection of Epidural Spinal Vascular Malformation in Klippel-Trenaunay Syndrome: Case Report
}

\author{
Ramon Navarro, Stephen Pirris*, Ricardo A. Hanel \\ Department of Neurosurgery, Mayo Clinic, Jacksonville, USA \\ Email: : Pirris.stephen@mayo.edu
}

Received 1 July 2014; revised 1 August 2014; accepted 1 September 2014

Copyright @ 2014 by authors and Scientific Research Publishing Inc.

This work is licensed under the Creative Commons Attribution International License (CC BY).

http://creativecommons.org/licenses/by/4.0/

(c) (i) Open Access

\begin{abstract}
Background: Klippel-Trenaunay-Weber syndrome is a rare congenital condition that may involve the central nervous system with extensive vascular malformations, and soft-tissue hypertrophy of the affected limb. Methods: A 51-year-old patient underwent previous procedures including decompressive laminectomy and endovascular embolization using Onyx and a self-expandable stent. However, recanalization of the malformation was observed, his symptoms progressed, and the decision was made to undergo selective surgical resection with intraoperative image guidance using Stealth system paired with the 0-arm. Results: Adequate decompression of the affected spinal cord and cervical roots were obtained, and the patient's symptoms improved. Conclusion: Since the typical anatomic landmarks were obliterated by the extensive vascular malformation and previous surgery, intraoperative image guidance proved to be very beneficial. This case reports on the usage of spinal navigation to efficiently dissect out the affected nerve roots and avoid vascular injury by referencing the Onyx and stent.
\end{abstract}

\section{Keywords}

Spinal Navigation, Vascular Malformation, Klippel-Trenaunay, Image Guidance, Endovascular Embolization

\section{Introduction}

Klippel-Trenaunay-Weber syndrome is a rare congenital condition characterized by nevus port-wine stain, ven-

*Corresponding author.

How to cite this paper: Navarro, R., Pirris, S. and Hanel, R.A. (2014) Endovascular Treatment and Selective Image Guided Partial Resection of Epidural Spinal Vascular Malformation in Klippel-Trenaunay Syndrome: Case Report. Open Journal of Modern Neurosurgery, 4, 196-201. http://dx.doi.org/10.4236/ojmn.2014.44035 
ous and lymphatic malformations, and soft-tissue hypertrophy of the affected limb. This syndrome can also affect the central nervous system with sometimes extensive vascular anomalies. There is no curative treatment for this condition, and therapeutic efforts are usually focused to a single area. In cases with involvement of multiple spinal levels, a careful tailored plan should be made to address the clinically symptomatic region and avoid wrong-level surgery. With recent advances in image guidance, accurate planning can be made to help the surgeon identify the surgical target intraoperatively. We present the case of a patient in whom multidisciplinary treatment was offered after failed initial treatment. Surgical navigation and intraoperative neuromonitoring were used to identify the affected symptomatic level and safely decompress the cervical nerve roots.

\section{Case Presentation}

This 51-year-old male presented with history of right arm weakness, had been previously submitted to C3-6 decompressive laminectomy and instrumented posterior fusion at an outside hospital for cervical stenosis. During surgery, a significant vascular malformation was noted and partially resected for spinal cord decompression. The patient presented to our facility with progressive pain and weakness in the C6-8 dermatomes and myotomes. On gross exam, the patient has a confluent dermal port-wine stain vascular anomaly involving the C6 dermatomal distribution and right arm hypertrophy consistent with Klippel-Trenaunay-Weber syndrome (Figure 1). Imaging revealed a vascular malformation involving the majority of the cervical spinal axis with complete involvement of the C2-6 vertebral bodies and all right foraminae down to T1 (Figure 2). The plan was to proceed with endovascular embolization of the symptomatic portion of the vascular malformation and possible surgery or radiosurgery to follow if neurologic recovery is not sufficient. The patient understood that there was no possible curative procedure.

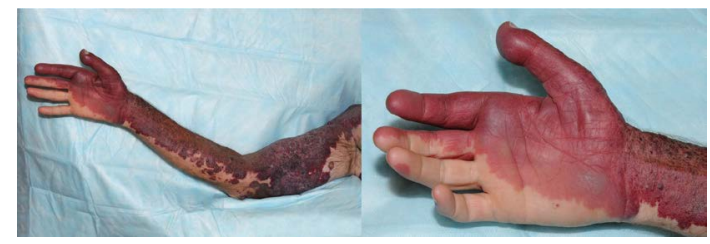

Figure 1. Digital photograph of the patient displaying his confluent dermal port-wine stain, vascular anomaly, and right arm hypertrophy, more evident on the thumb, consistent with Klippel-Trenaunay-Weber syndrome.

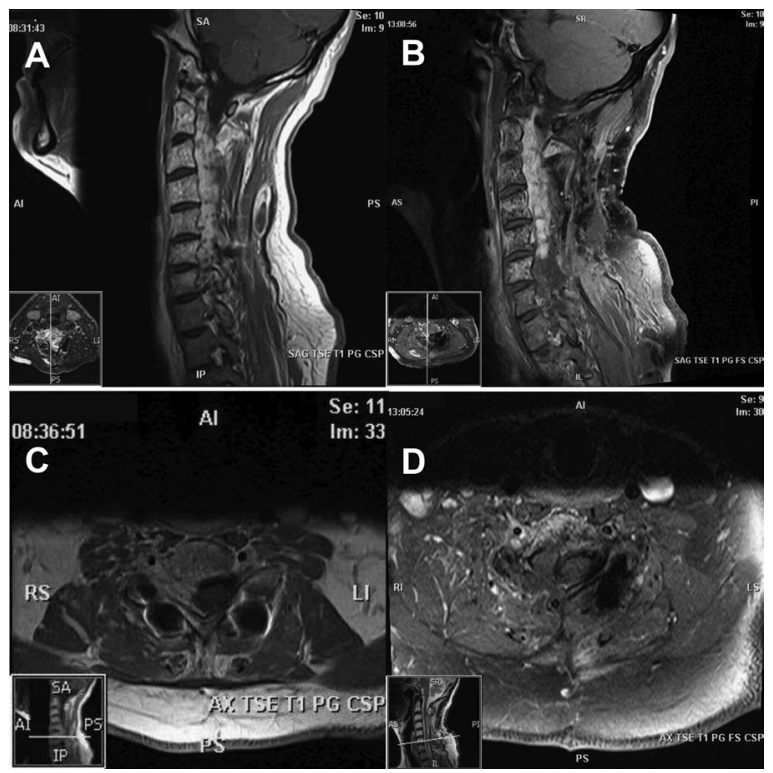

Figure 2. MRI with Sagittal ((A) and (B)) and C7 Axial ((C) and (D)) T1 with contrast images obtained pre$((\mathrm{A})$ and $(\mathrm{C}))$ and postoperatively ((B) and (D)) that display the extensive vascular malformation involving the entire cervical spine and the decompressive foraminotomies that were performed for partial resection of the malformation. 


\section{Methods/Operative Technique}

Treatment plan was started with a therapeutic spinal angiogram. The patient was placed under general anesthesia and neurophysiologic monitoring. A diagnostic angiogram was first performed showing a C5-C6 spinal vascular malformation fed by two arterial feeders from the right vertebral artery and, in a lesser extent, branches from the right thyro-cervical trunk. Selective micro-catheterization of the most superior feeder was achieved, and balloon-assisted embolization, to avoid reflux of the liquid agent into the vertebral artery, was performed using Onyx 18 (ev3, Irvine, California). The liquid material permeated well into the nidus and also occluded in a retrograde fashion the other vertebral feeder. Complete obliteration of the vertebral artery branches supply was achieved. However, when removing the microcatheter, Onyx stretched material was brought to the vertebral artery lumen, with mobile pediculated embolic material noticed in two angiographic runs. In order to prevent possible breakdown and potentially catastrophic vertebra-basilar artery emboli, an Enterprise self-expanding stent (Codman Neurovascular, Raynham, Massachusetts) was deployed to tackle the fragment against the vessel wall. Intraprocedural abciximab was given prior to stent deployment. No neuromonitoring changes were noted during the procedure, and the patient remained at his neurological baseline. Two months later, the angiogram was repeated showing patency of the vertebral artery stent, partial reopening of previous feeders and additional feeders from the right thyro-cervical trunk, specifically the right ascending cervical artery (Figure 3). This feeder was far more noticeable than in previous angiograms and could represent vascular recruitment from the spinal malformation. No further endovascular intervention was performed, and the decision was made to proceed with open targeted surgical decompression. Surgery was chosen over radiosurgery in order to achieve a faster clinical improvement and avoid possible nerve root radiation damage.

Stealth (Medtronic Inc., Littleton, Massachusetts) system paired with the O-ARM (Medtronic Navigation, Louisville, Colorado) was used for 3-dimensional (3D) image guidance in this case. The O-ARM produces intraoperative cone-beam computed tomography ( $\mathrm{cbCT}$ ) images, which are automatically registered to the Stealth image-guided system. In this case, the patient was placed prone on a short platform of a radiolucent spine table allowing for the head to be suspended and fixated by a skull clamp head holder. The reference arc of the image-guided system was attached to the head holder. An intraoperative cbCT scan was accomplished after exposure of the posterior elements of the cervical spine and removal of instrumentation on the right side. After the image acquisition, accuracy of the navigation system was checked and confirmed.

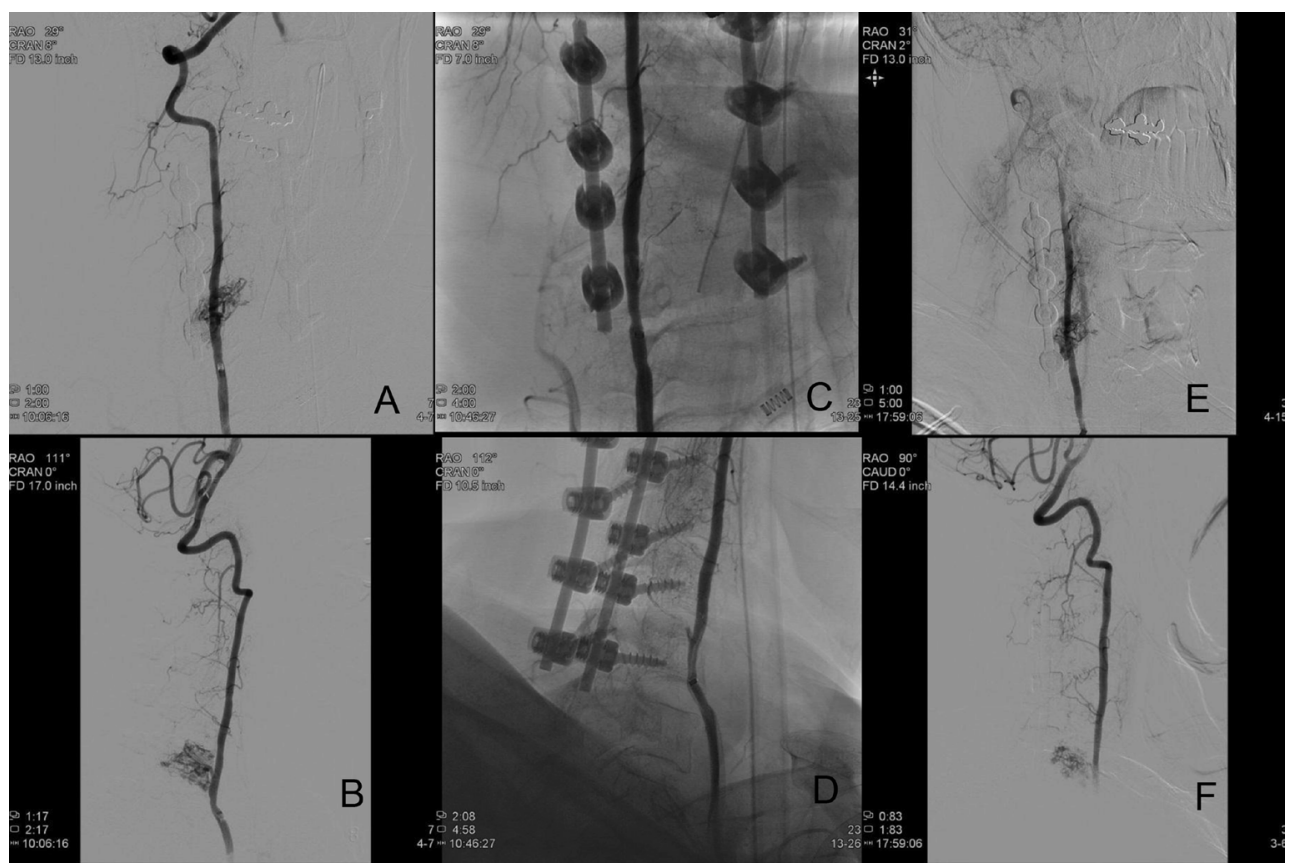

Figure 3. Angiographic views before Onyx embolization ((A) and (B)), immediately after embolization ((C) and (D)), and two months after the initial procedure ((E) and (F)). Significant reopening of the feeding vessels can be noticed coming from muscular branches of the right vertebral artery. 
We used the image guidance to first define the residual bony anatomy under the dense scar tissue and trace the course of the embolized vessels. After exposing the remaining bone laterally on the right side from C5-T1, decompressive foraminotomies were performed in standard fashion to decompress the C6, C7, and C8 nerve roots. Intraoperative neuromonitoring was used during the procedure. The scar tissue and vascular malformation obliterated the typical dissection planes, and image guidance was utilized for continued reorientation. The previously embolized feeding vessel was identified using image guidance, and it was traced back to the vertebral artery (Figure 4). This established our boundaries for resection of the vascular malformation, which was removed with conventional microvascular surgical techniques. There were no major vascular injuries noted, and the estimated blood loss was 300 cc.

\section{Results}

\section{Postoperative Course}

The patient expected incisional pain but no new neurologic deficits. His strength in the C6-8 myotomes improved from 3/5 to 4/5 (Medical Research Council [MRC] Scale for Muscle Strength) [1], and he was discharged home on postoperative day 3. At six months follow-up, he remains clinically stable with continued strength improvement. No plans for further angiographic follow-up are made unless there is a clinical deterioration since we acknowledge that the treatment was palliative with no intention of complete angiographic cure.

\section{Discussion}

Since its introduction in the mid-1990s, image-guided technologies have become a leading topic in all branches of spine surgery [2] [3]. In current practice, the vast majority of spinal image guidance is used to guide instrumentation placement. Three-dimensional (3D) image guidance has been reported to navigate posterior cervical anatomy to aid in accurate instrumentation placement [4] [5]. This is the first case report showing the usefulness of spinal image guidance using a preoperative endovascular embolization agent as a navigable landmark to selectively decompress an extensive vascular malformation.

Klipel-Trenaunay-Weber syndrome is defined by a clinical triad that includes venous varices, cutaneous capillary malformation, and tissue hypertrophy [6]. Vascular malformations are an important feature of this syndrome, and they might involve the nervous system. These might be multiple, include different levels and be lo-
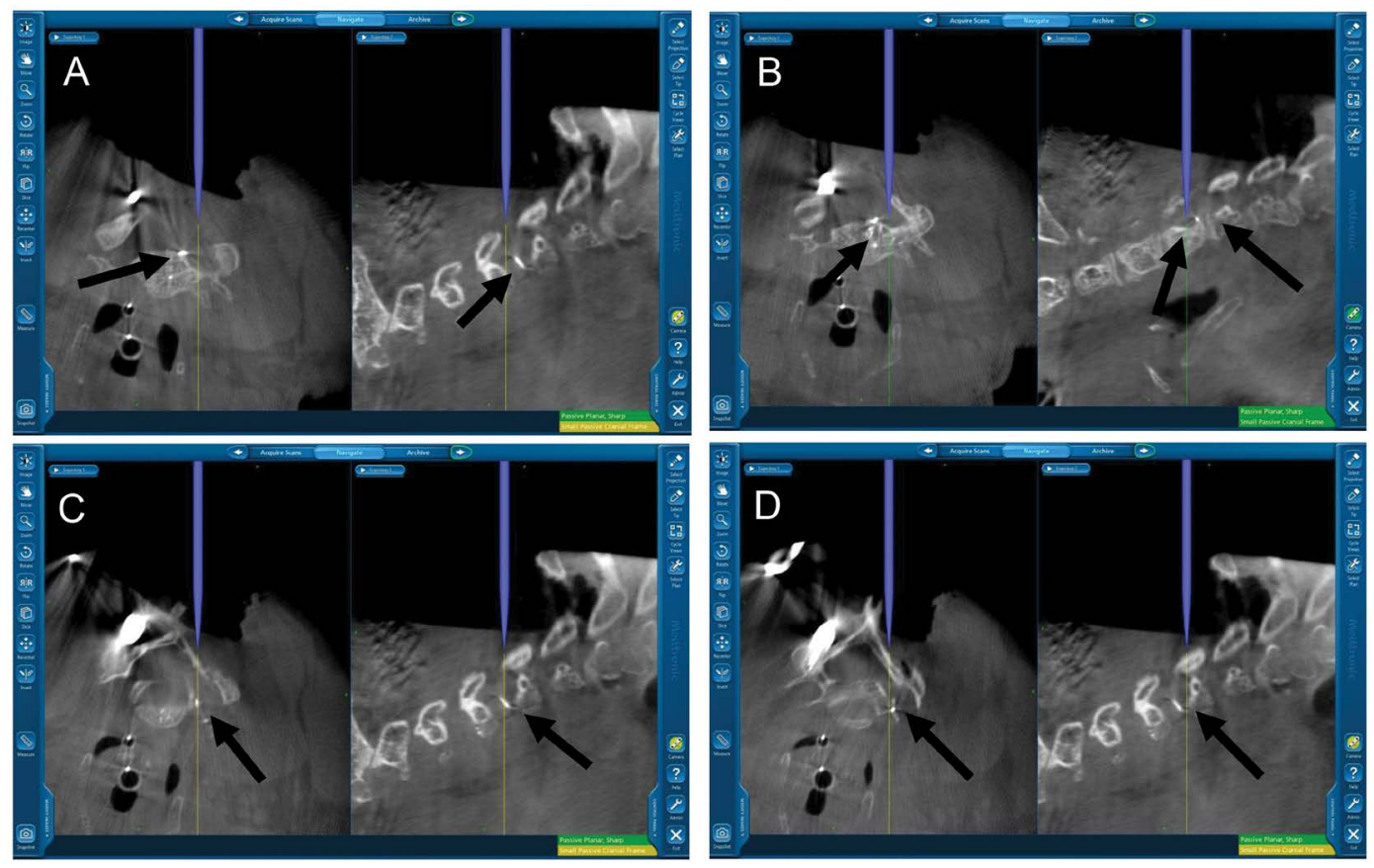

Figure 4. Intraoperative images ((A)-(D)) showing navigation of the course of the embolized vessel branches and defining the surrounding postoperative bony anatomy (black arrows are pointing to the embolized vessels). 
cated in the extradural and/or intradural space [7] [8]. Therefore, it is even more critical to focus the treatment to the symptomatic level. For this, appropriate localization is crucial. Performing the decompression at a level other than planned (i.e., "wrong level surgery") is a significant risk in this patient population with an extensive metameric malformation due to the presence of vascular pathology at multiple and often contiguous cervical levels. In addition to the landmarks provided by the stent and the Onyx cast, we used the O-arm to localize the level that needed surgical decompression after vascularity was diminished with endovascular embolization. The radiodense Onyx and stent tines provided vascular landmarks that the surgeons could easily identify with the navigation system to help guide the vascular resection.

Onyx as a nonadhesive embolic material is being increasingly used for the treatment of central nervous vascular malformations instead of n-butyl-cyanoacrylate (NBCA) [9]. Polymerization characteristics provide improved control during embolization, allowing the embolic agent to permeate the malformation; however, it often starts filling the draining veins and other arterial feeders, as in our case. Although Onyx reflux can be readily noticed and controlled, migration of the embolic material when removing the microcatheter is rather unusual. Despite use of compliant balloon to prevent reflux into the vertebral artery, onyx material migration did occur, which prompted us to deploy a stent in the vertebral artery to protect the vessel from occlusion and emboli. As expected in a complex vascular lesion, the complete obliteration of the lesion was transient, with recanalization demonstrated only two months after the initial procedure, demonstrating that standalone embolization was not effective in this patient. Nevertheless, Onyx radio-opacity made the lesion traceable during surgery with any xray modality and brings additional markers to identify the correct level for surgery.

\section{Conclusion}

The authors present a combined endovascular and surgical imaged guided spinal vascular malformation targeted resection. In addition, preoperative embolization with Onyx and placement of vertebral artery stent provided landmarks that were easily noted on the image guidance system. These landmarks significantly improved the safety of the difficult procedure by allowing for early identification and avoidance of the vertebral artery, which was deeply invested in the vascular malformation. The authors were then able to fully decompress the exiting nerve roots and resect the intended levels of the vascular malformation without causing damage to the vertebral artery.

\section{Acknowledgements}

The authors thank Victoria L. Jackson, MLIS (Academic and Research Support, Mayo Clinic, Jacksonville, FL) for her editorial assistance in the preparation of this manuscript.

\section{Sources of Funding/Disclosures}

The authors did not receive any financial support in the preparation of this manuscript. R.H. is a consultant for Covidien. The other authors have nothing to disclose.

\section{References}

[1] Alexander, M.J., Grossi, P.M., Spetzler, R.F. and McDougall, C.G. (2002) Extradural Thoracic Arteriovenous Malformation in a Patient with Klippel-Trenaunay-Weber Syndrome: Case Report. Neurosurgery, 51, 1275-1278; Discussion, 1278-1279. http://dx.doi.org/10.1097/00006123-200211000-00025

[2] Council, M.R. (1976) Aids to Examination of the Peripheral Nervous System, Memorandum No. 45. Her Majesty’s Stationary Office, London.

[3] Jacob, A.G., Driscoll, D.J., Shaughnessy, W.J., Stanson, A.W., Clay, R.P. and Gloviczki, P. (1998) Klippel-Trenaunay Syndrome: Spectrum and Management. Mayo Clinic Proceedings, 73, 28-36. http://dx.doi.org/10.1016/S0025-6196(11)63615-X

[4] Lanzino, G., D’Urso, P.I., Kallmes, D.F. and Cloft, H.J. (2012) Onyx Embolization of Extradural Spinal Arteriovenous Malformations with Intradural Venous Drainage. Neurosurgery, 70, 329-333. http://dx.doi.org/10.1227/NEU.0b013e318230929e

[5] Nolte, L.P., Visarius, H., Arm, E., Langlotz, F., Schwarzenbach, O. and Zamorano, L. (1995) Computer-Aided Fixation of Spinal Implants. Journal of Image Guided Surgery, 1, 88-93.

http://dx.doi.org/10.1002/(SICI)1522-712X(1995)1:2<88::AID-IGS3>3.0.CO;2-H 
[6] Nolte, L.P., Zamorano, L., Visarius, H., Berlemann, U., Langlotz, F., Arm, E., et al. (1995) Clinical Evaluation of a System for Precision Enhancement in Spine Surgery. Clinical Biomechanics (Bristol, Avon), 10, 293-303. http://dx.doi.org/10.1016/0268-0033(95)00004-5

[7] Nottmeier, E.W. and Young, P.M. (2010) Image-Guided Placement of Occipitocervical Instrumentation Using a Reference Arc Attached to the Headholder. Neurosurgery, 66, 138-142. http://dx.doi.org/10.1227/01.NEU.0000346264.66833.B3

[8] Richter, M., Cakir, B. and Schmidt, R. (2005) Cervical Pedicle Screws: Conventional versus COMPUTER-Assisted Placement of Cannulated Screws. Spine (Phila Pa 1976), 30, 2280-2287. http://dx.doi.org/10.1097/01.brs.0000182275.31425.cd

[9] Rohany, M., Shaibani, A., Arafat, O., Walker, MT., Russell, E.J., Batjer, H.H., et al. (2007) Spinal Arteriovenous Malformations Associated with Klippel-Trenaunay-Weber Syndrome: A Literature Search and Report of Two Cases. American Journal of Neuroradiology (AJNR), 28, 584-589. 
Scientific Research Publishing (SCIRP) is one of the largest Open Access journal publishers. It is currently publishing more than 200 open access, online, peer-reviewed journals covering a wide range of academic disciplines. SCIRP serves the worldwide academic communities and contributes to the progress and application of science with its publication.

Other selected journals from SCIRP are listed as below. Submit your manuscript to us via either submit@scirp.org or Online Submission Portal.
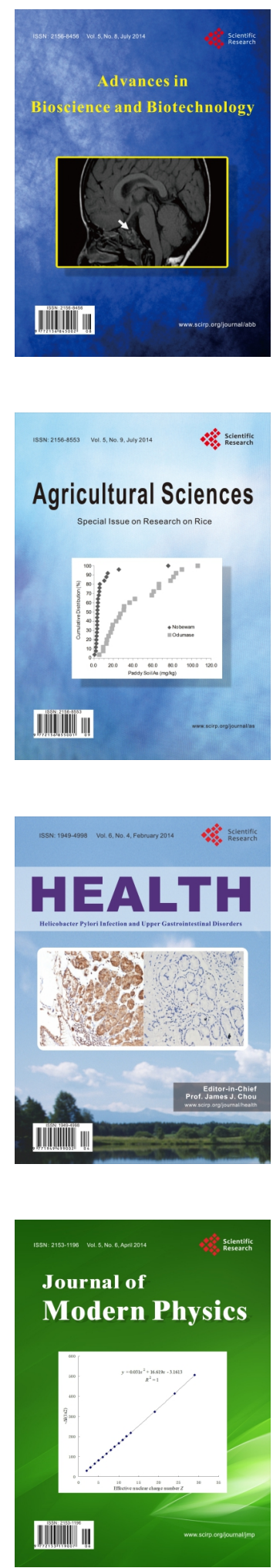
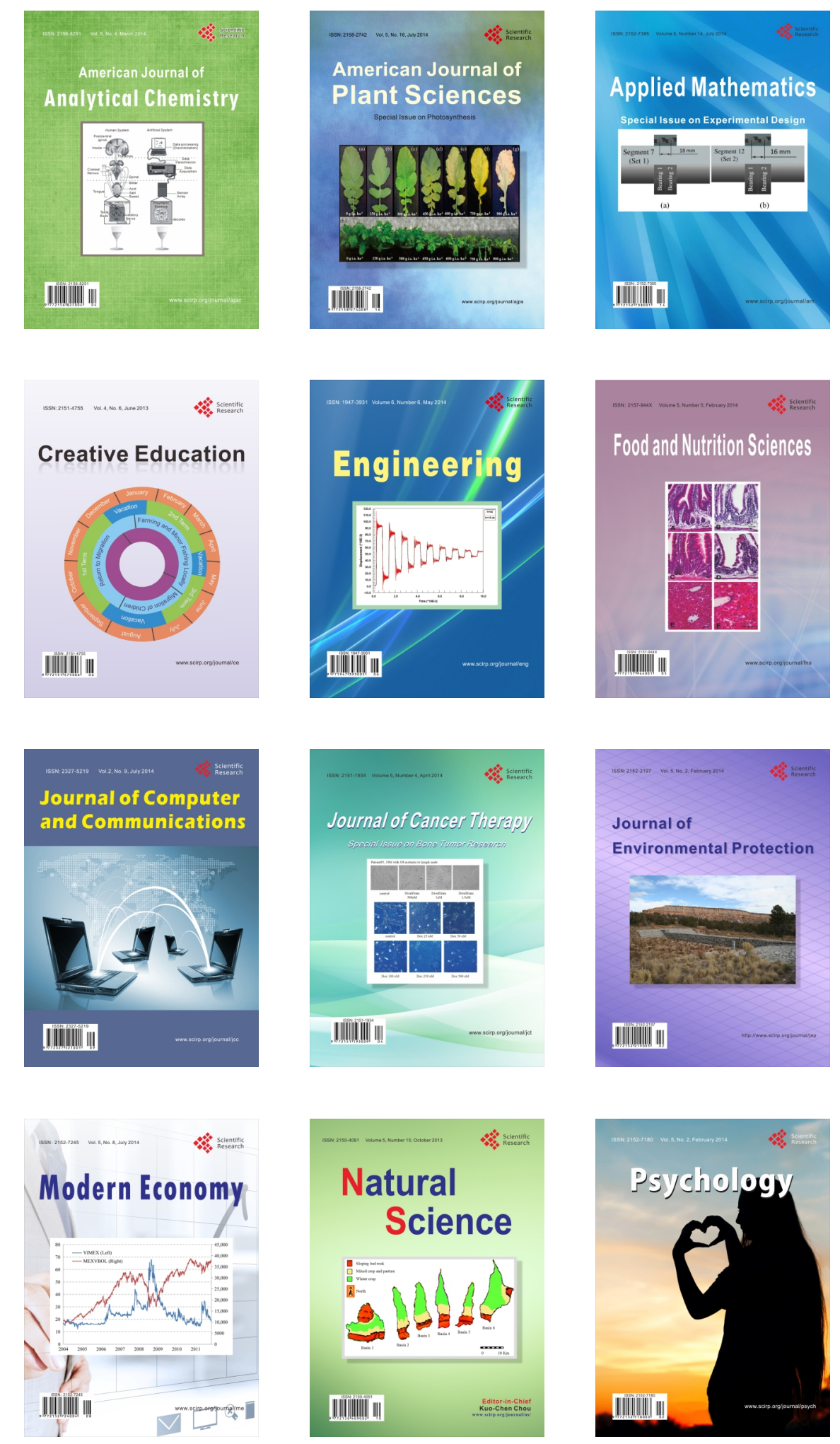